devices (Penumbra ${ }^{\circledR}$, Alameda, CA). Mean fluoroscopy time and dose area product, as well as standard deviations were calculated for each technique and compared using Student's ttest.

Results The fluoroscopy time and dose area product for interventional management of vascular occlusions using suction aspiration and stent retriever devices in a selected group of patients is given in the table.

\begin{tabular}{|c|c|c|c|c|c|}
\hline \multicolumn{3}{|c|}{ Suction aspiration } & \multicolumn{3}{|c|}{ Stent retriever } \\
\hline Vessel & $\begin{array}{l}\text { Fluoroscopy } \\
\text { time } \\
\text { (minutes) }\end{array}$ & $\begin{array}{l}\text { Dose area } \\
\text { product } \\
\left(\mathrm{mGy}-\mathrm{cm}^{2}\right)\end{array}$ & Vessel & $\begin{array}{l}\text { Fluoroscopy } \\
\text { time } \\
\text { (minutes) }\end{array}$ & $\begin{array}{l}\text { Dose area } \\
\text { product } \\
\left(\mathrm{mGy}-\mathrm{cm}^{2}\right)\end{array}$ \\
\hline Left M1 & 18.33 & 612188 & Left M1 & 17.25 & 451328 \\
\hline Left M1 & 25.17 & 333391 & Left M1 & 9.8 & 262116 \\
\hline Right M1 & 6.92 & 185136 & Right M1 & 12.85 & 273798 \\
\hline Right M1 & 31.07 & 832479 & Right M1 & 13.78 & 447020 \\
\hline Right M1 & 21.03 & 398619 & Right M1 & 8.4 & 198648 \\
\hline Mean & 20.50 & 472363 & Mean & 12.42 & 326582 \\
\hline $\begin{array}{l}\text { Standard } \\
\text { Deviation }\end{array}$ & 8.99 & 253222 & $\begin{array}{l}\text { Standard } \\
\text { Deviation }\end{array}$ & 3.48 & 115516 \\
\hline $\begin{array}{l}\text { P-value } \\
\text { (FT) }\end{array}$ & 0.048 & & $\begin{array}{l}\text { P-value } \\
\text { (DAP) }\end{array}$ & 0.137 & \\
\hline
\end{tabular}

Conclusion Data from this limited subset of patients suggest a statistically significant difference in fluoroscopy time for mechanical thrombectomies performed with stent retrieval versus those performed with suction aspiration. No significant difference was seen in dose area product data.

The difference in fluoroscopy time between the two techniques may reflect operator comfort rather than intrinsic differences between the two techniques. Notably, however, these data were obtained across multiple operators at our institution, so it may be plausible that these differences are generalizable to technique. It is important to again note that these differences in radiation exposure are unlikely to result in clinical effect in an individual patient, but differences in exposure to the operator over a career may be significant. Further exploration with larger patient samples is warranted.

Disclosures P. Brown: None. M. Cobb: None. T. Smith: None. A. Zomorodi: None. L. Gonzalez: None.

\section{E-070 ENDOVASCULAR TECHNIQUES FOR ACHIEVEMENT OF BETTER FLOW DIVERTER WALL APPOSITION}

${ }^{1} \mathrm{~A}$ Kuhn, ${ }^{1} \mathrm{~K}$ de Macedo Rodrigues, ${ }^{1} \mathrm{M}$ Gounis, ${ }^{2} \mathrm{P}$ Kan, ${ }^{1} \mathrm{M}$ Marosfoi, ${ }^{1} \mathrm{~J}$ Lozano, ${ }^{1} \mathrm{M}$ Perras, ${ }^{1} \mathrm{C}$ Brooks, ${ }^{1} \mathrm{M}$ Howk, ${ }^{1} \mathrm{D}$ Rex, ${ }^{1} \mathrm{~F}$ Massari, ${ }^{1} \mathrm{~A}$ Wakhloo, ${ }^{1} \mathrm{~A}$ Puri. ${ }^{1}$ Division of Neuroimaging and Intervention, Department of Radiology and New England Center for Stroke, University of Massachusetts, Worcester, MA; ${ }^{2}$ Department of Neurosurgery, Baylor College of Medicine, Houston, TX

\subsection{6/neurintsurg-2016-012589.142}

Purpose Flow diverter malapposition as a technical complication with the use of the pipeline embolization device has been described and maybe is associated with delayed ischemic events or potentially delayed life-threatening aneurysm rupture. We describe our endovascular techniques for manipulation of flow diverters in order to achieve proper vessel wall apposition.
Materials and methods We retrospectively analyzed our flow diverter database and included all patients in whom malapposition of the device was detected on follow-up angiography immediately after device deployment. We then evaluated feasibility and technical success of different endovascular approaches aimed to correct the inadequate vessel wall apposition. Successful endovascular techniques for manipulation of the device included use of wires, catheters and additional devices. Final confirmation of flow diverter wall apposition prior to completion of the intervention was performed using 3D multi-planar cone-beam CT reconstruction images.

Results We identified 5 successful endovascular techniques for better flow diverter wall apposition: 1) Use of a wire with a J, pigtail or S-shaped tip passed through the device, 2) Manipulation with a microcatheter, which can be used to press the PED against the vessel wall, 3) Balloon angioplasty of the malapposed segment, 4) Manipulation with an intermediate catheter, which can be used at the proximal edge or within the flow diverter to push the PED against the vessel wall, 5) Placement of another flow diverter within the previously placed FD to better oppose the ends and 6) Placement of an open-cell stent in telescopic fashion across the malapposed portion of the PED (proximal or distal edge). The Neuroform stent with its high outward radial force is an excellent adjunct treatment option to anchor the malapposed flow diverter against the vessel wall while permitting perforator patency.

Conclusion Flow diverter malapposition can be addressed successfully during the interventional procedure using a variety of techniques. This may prevent devastating delayed complications.

Disclosures A. Kuhn: None. K. de Macedo Rodrigues: None. M. Gounis: 1; C; NIH, Medtronic Neurovascular, Microvention/Terumo, Cerevasc LLC, Gentuity, Codman Neurovascular, Philips Healthcare, Stryker Neurovascular, Tay Sachs Foundation, and InNeuroCo Inc. 2; C; Codman Neurovascular and Stryker Neurovascular. 4; C; InNeuroCo Inc. P. Kan: 2; C; Stryker Neurovascular, Covidien, and MicroVention. M. Marosfoi: None. J. Lozano: None. M. Perras: None. C. Brooks: None. M. Howk: None. D. Rex: None. F. Massari: None. A. Wakhloo: 1; C; NIH, Philips Healthcare, Wyss Institute. 2; C; Codman Neurovascular and Stryker Neurovascular. 3; C; Harvard Postgraduate Course, Miami Cardiovascular Institute. 4; C; InNeuroCo Inc, EpiEB and Pulsar Medical. A. Puri: 1; C; Stryker Neurovascular and Covidien. 2; C; Codman Neurovascular, Stryker Neurovascular and Covidien. 3; C; Miami Cardiovascular Institute. 4; C; InNeuroCo Inc.

\section{E-071 INITIAL EXPERIMENTAL RESULT OF A NOVEL, LOW PROFILE STENT FOR ANEURYSM TREATMENT}

I Kan, Y Murayama, K Karagiozov, A Ikemura, I Yuki, H Takao, T Kodama. Neurosurgery, The Jikei University School of Medicine, Tokyo, Japan

\subsection{6/neurintsurg-2016-012589.143}

Introduction Stent assisted coil therapy has been developed for treatment of wide neck aneurysms. However, several reports show that recanalization rate of $10-15 \%$ after therapy is still observed. A novel low profile, flow diverter stent has been developed, and initial experience with it in an experimental wide-neck aneurysm swine model is reported.

Method The novel stent is self-expandable with radiopaque markers on both ends and 0.023 inch inner size compatible 
microcatheter. Eighteen aneurysms in 9 swine were surgically created using vein auto-grafts. Embolizations were performed in following device combinations: Novel Stent with coil (Group1: Novel stent, $\mathrm{n}=6$ ), commercially available stent (Group2: Neuroform stent, $\mathrm{n}=6$ ) with coil, and coil alone (Group3: coil, $\mathrm{n}=6$ ). Swine were sacrificed 14 days after stent deployment.

Results Mean aneurysm neck size was $6.24 \mathrm{~mm} \mathrm{(4.3-8.26}$ $\mathrm{mm})$, and average aneurysm fundus size was $9.0 \mathrm{~mm}$ (5.8$10.9 \mathrm{~mm}$ ). All cases in Group2 were treated by Neuroform stent. Average VER (volume embolization ratio) of Group1, Group2, and Group3 was 10.1\%, 10.9\%, and 10.5\%, respectively. There were no technical complications during novel stent deployment, such as migration, occlusion, etc. Favorable angiographic outcome, such as complete aneurysm thrombosis, was observed in 50\% of group3, and there was no favorable outcome in both group2 and 3. Recanalization rate of group1, 2 , and 3 is $50 \%(\mathrm{n}=3), 100 \%(\mathrm{n}=6)$, and 66\% $(\mathrm{n}=4)$, respectively. Aneurysmal rupture after procedure was observed in three cases from group 2, and two cases from group 3.

Conclusion The present study showed promising initial experience with the novel stent, particularly for its role as a low profile flow diverting stent and as an assisting stent for coil therapy.

Disclosures I. Kan: 1; C; Japan Agency for Medical Research and Development. Y. Murayama: 1; C; Japan Agency for Medical Research and Development. K. Karagiozov: None. A. Ikemura: None. I. Yuki: None. H. Takao: None. T. Kodama: None.

\section{E-072 50 SHADES OF GRADIENTS: DOES THE PRESSURE GRADIENT IN VENOUS SINUS STENTING FOR IDIOPATHIC INTRACRANIAL HYPERTENSION MATTER?}

${ }^{1} \mathrm{C}$ McDougall, ${ }^{2} \mathrm{~J}$ Beecher, ${ }^{2} \mathrm{~V}$ Shen Ban, ${ }^{1} \mathrm{M}$ Fiesta, ${ }^{1} \mathrm{~J}$ Barr, ${ }^{2} \mathrm{~J}$ White, ${ }^{1} \mathrm{R}$ Novakovic, ${ }^{1} G$ Pride, ${ }^{2} \mathrm{~B}$ Welch. ${ }^{1}$ Radiology, University of Texas Southwestern, Dallas, TX; ${ }^{2}$ Neurosurgery, University of Texas Southwestern, Dallas, TX

\subsection{6/neurintsurg-2016-012589.144}

Introduction Idiopathic intracranial hypertension (IIH) is a relatively uncommon, poorly understood disease that is often difficult to treat. First line medical and surgical therapies are often ineffective. Venous sinus stenosis is found in the vast majority of patients with IIH and venous sinus stenting (VSS) has been demonstrated to be effective in a select patient group. Identifying which patients will benefit from stenting remains unclear. One strategy is to measure the pressure gradient across the stenosis using retrograde transvenous manometry. Many authors have adopted a strategy whereby VSS is offered to patients with a pressure gradient above a certain threshold. This number is variable between different operators. In this study we reviewed the literature to try and establish what if any evidence exists to support a relationship between the pressure gradient across the stenosis and clinical outcomes. Materials and methods We systematically reviewed the English literature for studies reporting both the pressure gradients across the stenosis for each patient and the individual patient outcomes. Data was then analyzed for statistical correlations between the pressure gradient and the outcome.

Results We identified 85 patients from 13 studies in which both the pressure gradient and clinical outcomes were reported for each patient.

ANOVA comparing gradients with outcomes was not significant $(p=0.06)$. Student's $t$-test analysis of the groups with a dichotomization between the group with favorable outcomes and those with unfavorable outcomes was also not significant $(p=0.13)$. The pressure gradient was not found to be a statistically significant predictor of outcome on univariate logistic regression analysis $(p=0.15)$.

Conclusion Venous sinus stenting for IIH appears to have good clinical results in selected cases. However, from the available reported cases in the literature, there does not appear to be any correlation between an increasing pressure gradient across the region of stenosis and the chances of an improved outcome. These findings underscore the need for further study of IIH and reflect our incomplete understanding of its exact pathophysiology.

Disclosures C. McDougall: None. J. Beecher: None. V. Shen Ban: None. M. Fiesta: None. J. Barr: None. J. White: None. R. Novakovic: None. G. Pride: None. B. Welch: None.

\section{E-073 HIGH RESOLUTION MAGNETIC RESONANCE IMAGING OF INTRACRANIAL ANEURYSMS TREATED BY FLOW DIVERSION}

1J Guan, ${ }^{2} \mathrm{~S}$ McNally, ${ }^{3} \mathrm{~A}$ de Havenon, ${ }^{1} \mathrm{P}$ Tuassky, ${ }^{2} \mathrm{~S}$ Kim, ${ }^{1} \mathrm{M}$ Park. ${ }^{1}$ Neurosurgery, University of Utah, Salt Lake City, UT; ${ }^{2}$ Radiology and Imaging Sciences, University of Utah, Salt Lake City, UT; ${ }^{3}$ Neurology, University of Utah, Salt Lake City, UT

\subsection{6/neurintsurg-2016-012589.145}

The use of flow diverters to treat intracerebral aneurysms is highly successful with a low rate of morbidity of mortality.

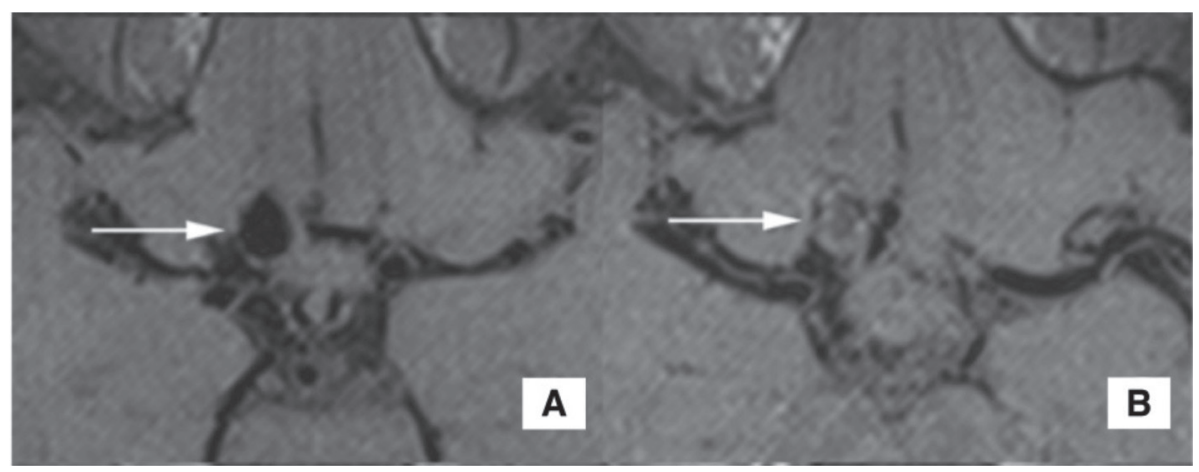

Abstract E-073 Figure 1 A) Pre-flow diversion 3D T1w Black Blood pre-contrast image; B) Post-flow diversion 3D T1w Black Blood pre-contrast image 